\title{
Evaluation in Moves: An Integrated Analysis of Chinese MA Thesis Literature Reviews
}

\author{
Jianping $\mathrm{XIE}^{1}$ \\ ${ }^{1}$ School of English and Education, Guangdong University of Foreign Studies, Guangzhou, China \\ Correspondence: Jianping XIE, School of English and Education, Guangdong University of Foreign Studies, 178 \\ Waihuang Donglu, Guangzhou Higher Education Mega Center, Guangzhou, 510006, China. Tel: \\ 86-135-8039-2269. E-mail: zdqxjp@163.com
}

Received: October 6, 2016 Accepted: January 30, 2017 Online Published: February 2, 2017

doi: 10.5539/elt.v10n3p1 URL: http://doi.org/10.5539/elt.v10n3p1

\begin{abstract}
The ultimate communicative purpose of literature reviews is to convince the reader of the worthiness of the writer's research, which is realized stage by stage and evaluation plays an important role in achieving this end. However, concerns about evaluation demonstration in novice academic writers' literature reviews have been repeatedly voiced in academia. This study examines how Chinese English-major MA students utilize evaluative resources in different rhetorical stages in thesis literature reviews and whether in a way that facilitates building a coherent argument for their own studies. To achieve this, an integrated appraisal analysis applying Martin and White's (2005) appraisal framework with a move analysis based on Kwan's (2006) model of the move structure of thesis literature reviews is undertaken. Results show that the Chinese students generally manipulate evaluative resources in a way that is beneficial for realizing the purposes of different rhetorical stages in thesis literature reviews. However, they also have problems in deploying generic structure and constructing evaluative stances, which hamper weaving a strong argument in the texts. Findings of this study provide implications for teaching English academic writing in China and in other L2 contexts as well.
\end{abstract}

Keywords: evaluation, appraisal analysis, move analysis, thesis literature reviews

\section{Introduction}

In academic writing, writers express their emotions, opinions, attitudes, and positions towards various entities or propositions talked about via various evaluative resources (e.g., reporting verbs, hedges, boosters, modality), so as to "construct a dialogue and relations of solidarity with the reader and to structure the text in expected ways" (Hyland \& Diani, 2009). Literature review is "a defining feature of nearly all academic and research writing" (Feak \& Swales, 2009), whose communicative purpose is to convince the reader of the worth of the writer's study (Bunton, 2002). A large number of previous studies on literature reviews (e.g., Hart, 1998; Boote \& Beile's, 2005; Machi \& McEvoy, 2009; Dawidowicz, 2010) concern how to assess literature reviews or provide guidance about literature review writing for novice academic writers, and all these studies emphasize the importance of evaluation and coherent argument in literature reviews. However, practitioners in undergraduate and graduate education often voice their concerns about evaluation demonstration in novice (especially L2) academic writers' literature reviews, as which tend to be "thinly disguised annotated bibliographies" (Hart, 1998) that "need something more to evaluate and connect" (Swales \& Lindemann, 2002). Therefore, how to improve students' abilities in demonstrating evaluative stances in literature review writing remains a challenging issue in L2 writing pedagogy.

Another major strand of literature on literature reviews focus on the generic structure of literature reviews. Since the seminal work of Swales (1990) with his influential model of Creating A Research Space (CARS), the generic structure of literature reviews has also been frequently studied (e.g., Shaw, 1991; Ridley, 2000; O'Connell \& Jin, 2001; Kwan, 2006). For instance, O'Connell and Jin (2001) analyzed and compared the structure of five literature reviews by Chinese postgraduate students at British universities with a literature review model promoted by well-established western academics: Move 1, statement of problem issues; Move 2, findings related to the problem issues; Move 3, critical analysis of findings; Move 4, identification of gaps, and Move 5, summation and transition to the next section. The authors found that all the Chinese students' literature reviews include some of the key characteristics matching those of a good literature review, but Move 3, critical analysis, only appeared 
in one student's literature review. O'Connell and Jin then accounted for the Chinese students' lack of critical analysis as a result of their tendency to appreciate rather than criticize the literary values of a text. Based on a corpus of $20 \mathrm{Ph} . \mathrm{D}$. theses literature review chapters by NS students of applied linguistics, Kwan (2006) identified the generic structure of thesis literature reviews, which exhibits an introduction-body-conclusion schematic structure with the body comprising recursive move structures that are fairly similar to thesis introductions.

Without doubt, the move analyses help to reveal the goal-oriented rhetorical stages of literature reviews, which are also conducive to enhancing students' metalinguistic awareness and assists the teaching in modeling sample texts. However, move analyses are solely oriented towards the textual meaning of language, and viewing from the metafunctional perspective (Halliday, 1994), the present researcher argues that it would be more insightful if evaluative meanings were taken into account, thus revealing how the interpersonal interacts with the textual in realizing the communicative purpose of literature reviews. On the other hand, the move analysis would help "locate" and contextualize the evaluative instantiations and enable a closer and better understanding as when and why the academic writers construct their evaluative stances in the way they are. Actually, such integrated attempts are not uncommon in the literature. For example, Crane (2008) conducted a contrastive textual analysis of evaluative features in different rhetorical stages of letters written by L1 and L2 writers of German. Chang and Schleppegrell (2011) linked the engagement resources with the rhetorical purposes in research article introductions and generated illuminating implications for L2 writing pedagogy.

Adopting such an integrated approach, this study investigates evaluations in different generic stages of thesis literature reviews written by Chinese English-major MA students, aiming to find out how they utilize evaluative resources to serve different argumentative purposes in different stages and whether in a way that facilitates weaving a strong and coherent argument for their own studies. Findings of this study will provide implications for teaching English academic writing in China and other similar L2 contexts as well, especially in the case of teaching thesis literature review writing.

\section{Analytic Frameworks}

Martin and White's (2005) appraisal framework and Kwan's (2006) model of the move structure of thesis literature reviews are the analytic frameworks in this study.

\subsection{The appraisal framework}

This study adopts the appraisal approach because it provides a functional model of studying evaluative language at the discourse-semantic level, which enables a comprehensive exploration of the evaluative meanings both explicitly encoded at the lexico-grammatical level and implicitly encoded at the discourse-semantic level in academic discourse. White (2001) defined appraisal as a catch-all term encompassing all evaluative uses of language, including those by which the speaker/writer adopts particular value positions or stances, and by which they negotiate these stances with either actual or potential respondents.

The overall appraisal framework consists of three subsystems: attitude, graduation and engagement. The attitude system differentiates three types of attitude: affect (emotions and feelings: satisfied, unhappy), judgment (assessment of human character and behavior according to ethical norms: capable, reliable), and appreciation (evaluation of the social value of entities: critical, essential). Attitude can either be encoded explicitly and directly as inscribed, or implicitly and indirectly as evoked. Attitudes can be positive (e.g., an innovative study) or negative (e.g., an unclear description) in polarity. The graduation system identifies that values can be up-scaled or down-scaled in force (concerning intensity: very important, or quantity: few studies) or in focus (i.e., the boundaries of a categorical meaning: a real success). The engagement system addresses the voicing in texts as monoglossic (i.e., the speaker's/writer's solo voicing: This is an inspiring study.) or heteroglossic (i.e., multi-voicing: Smith said that this is an inspiring study.). The heterglossic way contracting refers to the situation when writers close down dialogues with other voices/positions via disclaiming other voices/positions or proclaiming the authorial voices/positions, whereas the heteroglossic way expanding refers to the situation when writers open up dialogues with other voices/positions via entertaining other possible voices/positions or attributing a position to an external source. Due to limited space, this paper will not elaborate on each category. Please refer to Martin and White (2005) for detailed information on each category. Figure 1 displays the appraisal taxonomy. 


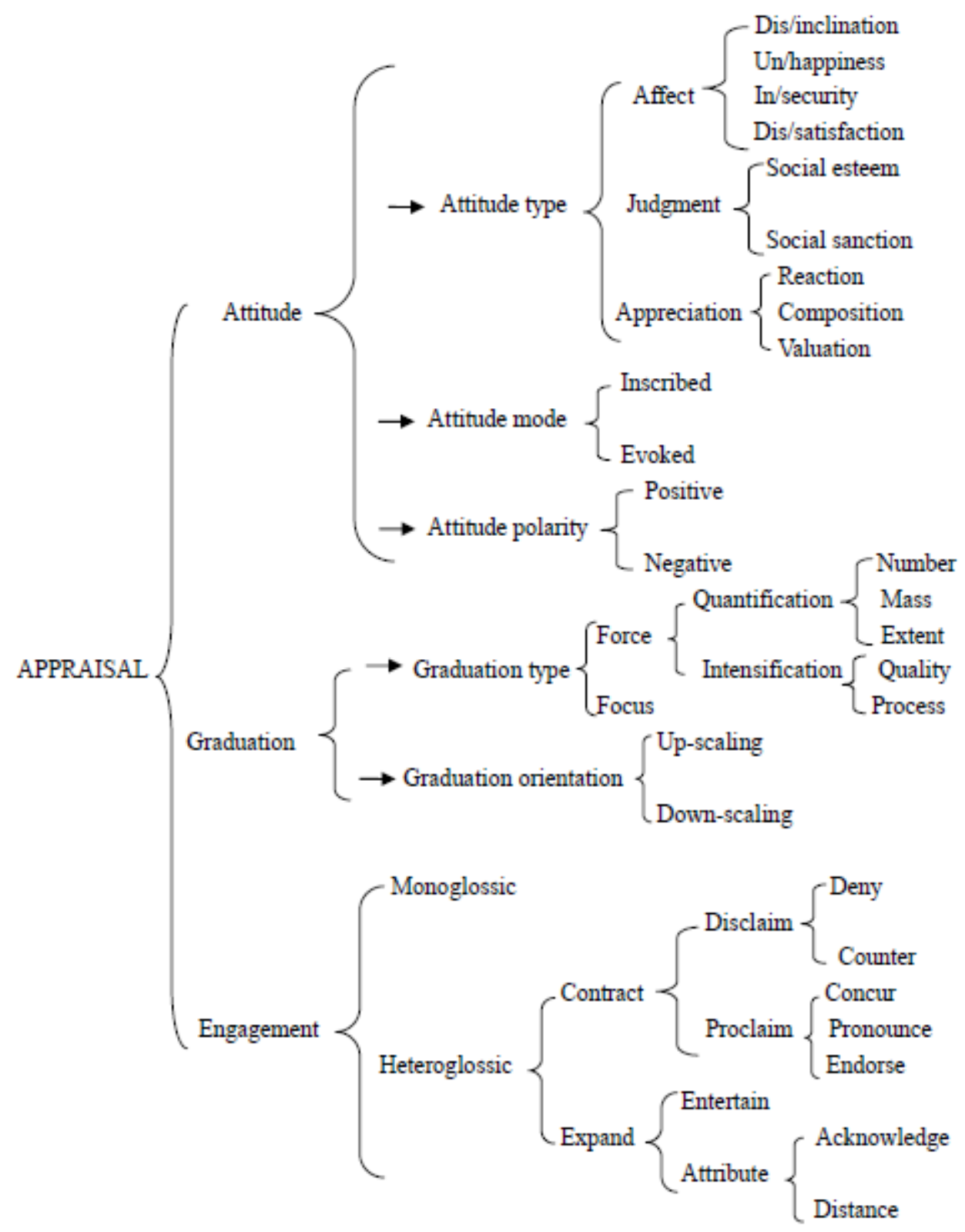

Figure 1. Appraisal framework (adapted from Martin \& White, 2005)

\subsection{Becky Kwan's (2006) Move Model of Thesis Literature Reviews}

Kwan's (2006) model is the most relevant to the present study because the model is also oriented towards thesis literature reviews. From Table 1, we can see that "in terms of rhetorical organization, literature review resembles an introduction chapter in that they follow a CARS model: they establish a territory, establish a niche, and then occupy that niche" (Thompson, 2009), but thesis writers resort to more heterogeneous ways to fulfill the purposes of the three moves and there is no strategy being unanimously used in literature review chapters. That is why, different from Swales'(1990) usage of the term step in the CARS model, Kwan uses the term strategy to refer to the non-obligatory and non-sequential constituents. The configuration of the obligatory and optional moves and strategies form the schematic structure of thesis literature reviews. 
Table 1. Kwan's (2006) model of the move structure of thesis literature review chapters

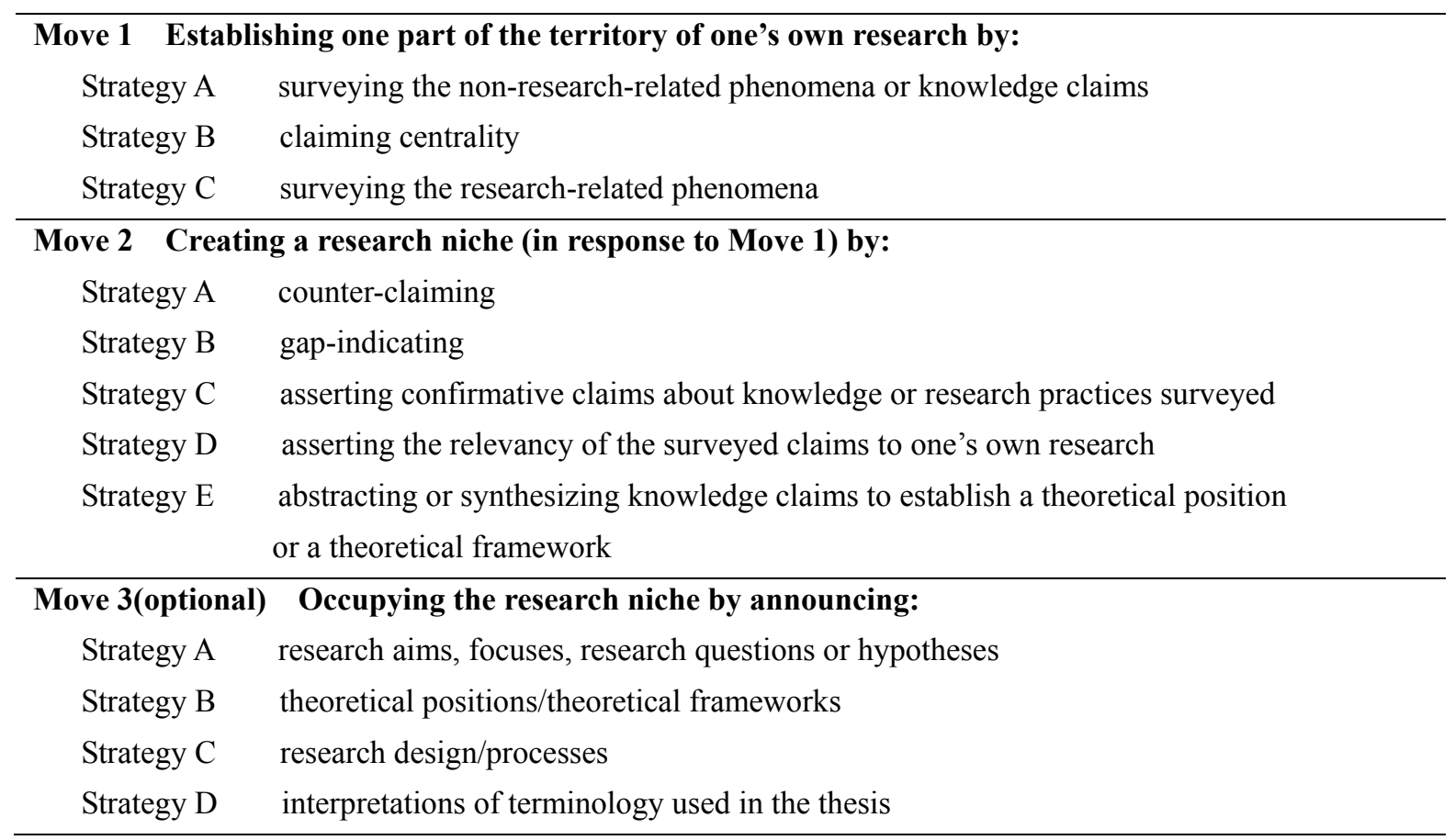

As many scholars (e.g., Hart, 2001; Turner \& Bitchener, 2008; Machi \& McEvoy, 2009) pointed out, literature review is in essence an extended persuasive argument built across the three moves for the worth of the writer's own study. Rhetorically, these three moves correspond to three arguments put forward by Hood (2006): (1) to argue for the writer's object of study, (2) to argue for a need for new knowledge, and (3) to argue for the writer's own contribution. In each move, the writer navigates evaluation to serve for a specific argument, and progressively achieves the ultimate purpose of literature reviews.

\section{Methodology}

A detailed textual analysis integrating the appraisal analysis and move analysis of Chinese English-major MA thesis literature reviews is undertaken in this study.

\subsection{The Texts}

Twenty-five Chinese MA thesis literature review chapters (ranging from 6000-7000 words, with a total of 167,099 words) covering various topics within the discipline of Applied English Linguistics from five prestigious universities in China in English studies from the year 2007 to 2011 were collected from China Master Dissertations Full-text Database, which is the only officially authorized electronic database that collects master's theses of all "hard" and "soft" disciplines of most of the tertiary institutions in China and available to registered users. The writers represent advanced mainland Chinese EFL learners whose English proficiency would normally not impede their expression of evaluations in English academic writing. Furthermore, to ensure a comparable quality of these texts, they were graded holistically according to Boote and Beile's (2005) Literature review scoring rubric by two raters, and the 25 chosen texts are of the level range of above $\mathrm{B}+$.

\subsection{Data Analysis}

First, a move analysis was conducted. Following Kwan's (2006) practice, those metadisursive introductory, transitive, and concluding paragraphs and sentences, section headings, figures, tables, endnotes and examples for illustration were excluded from the analysis. The researcher examined, classified and manually coded the text segments into different moves and strategies. Then five randomly chosen texts were coded by two external readers for a consistency check, which reached $85.7 \%$ agreement. The parts that were most often disagreed were Move 1 Strategy 1A and Strategy 1C. Then the discrepancies were discussed and recoded. Finally, the researcher revised these two ambiguous strategies in the rest of the data and had them reviewed by the external readers for a further check.

Second, an appraisal analysis was undertaken. Again, metadiscursive and illustrative languages were not included in the coding. In addition, seemingly attitudinal lexis and graduation lexis used in purely descriptive statements 
were not coded. The appraisal categories in the texts were manually coded and all together 14,697 appraising instantiations were identified and classified. Then the coding was reviewed by two external reviewers, which reached a good level of consistency and fairness, as only 206 appraisal items $(\approx 1.4 \%)$ were disagreed on by the reviewers, which were then discussed and recoded through clarification and elaboration of the defining criteria.

Finally, the distribution of evaluation in different rhetorical stages was analyzed. The occurrence frequencies of each appraisal category in each move and strategy were counted and compared. Normalized frequencies per $1,000 \operatorname{words}(/ \mathrm{k})$ instead of raw frequencies were calculated considering the varied length of the texts. To be exact, the appraising items were located in different strategies and then a tabular analysis was conducted, which helped to make the distribution of the appraisal categories more accessible for analysis and readily comparable. To exemplify, Table 2 provides a partial sample of the tabular analysis for the distribution of attitude in moves.

Table 2. Partial sample of tabular analysis of attitude in moves

\section{Attitude in moves in 10 NNU}

\begin{tabular}{|c|c|c|c|c|c|c|c|c|}
\hline \multirow{2}{*}{$\begin{array}{l}\text { Move } \\
\text { location }\end{array}$} & \multirow{2}{*}{ 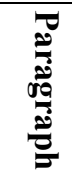 } & \multirow[b]{2}{*}{ Appraising items } & \multirow[b]{2}{*}{ Affect } & \multicolumn{2}{|c|}{ Judgment } & \multirow[b]{2}{*}{ Appreciation } & \multirow[b]{2}{*}{ Polarity } & \multirow[b]{2}{*}{ Mode } \\
\hline & & & & $\begin{array}{l}\text { Social } \\
\text { esteem }\end{array}$ & $\begin{array}{l}\text { Social } \\
\text { sanction }\end{array}$ & & & \\
\hline M1_StrA & $\mathrm{P} 1$ & $\begin{array}{l}\text { Intertextuality is one } \\
\text { of the underlying } \\
\text { features of texts. }\end{array}$ & & & & valuation & + & inscribed \\
\hline M2_StrB & P1 & $\begin{array}{l}\text { However, not } \\
\text { enough attention is } \\
\text { being paid to } \\
\text { non-literary } \\
\text { discourse }\end{array}$ & & capacity & & & - & inscribed \\
\hline M1_StrA & $\mathrm{P} 2$ & $\begin{array}{l}\text { It is significant to } \\
\text { note that Kristeva } \\
\text { coins the word } \\
\text { "intertextuality" and } \\
\text { calls people's } \\
\text { attention to it. }\end{array}$ & & & & valuation & + & inscribed \\
\hline
\end{tabular}

Note: M1_StrA stands for Move 1 Strategy A; M2_StrB stands for Move 2 Strategy B.

\section{Overview of the Generic Structure of the Texts}

Table 3 shows that Move 1 (Establishing one part of the territory of one's own research) and Move 2 (Creating a research niche) appear in all the 25 texts while Move 3 (Occupying the research niche) in 16 out of the 25 of the texts $(65 \%)$. This generic deployment is consistent with what was found in the doctoral thesis literature review chapters in Kwan's (2006) study.

For Move 1, Strategy 1A surveying the non-research-related phenomena or knowledge claims (i.e., making topic generalizations) and Strategy 1C surveying research-related phenomena (i.e., reviewing previous studies and research activities) appear in all the texts; while Strategy 1B claiming centrality (direct declaration of the importance of the writer's themes or of the necessity of reviewing the themes) is used in $52 \%$ of the texts. Under Move 2, Strategy 2B gap indicating (i.e., indicating the scarcity or lack of knowledge in current epistemic pursuits) is the most frequently used strategy (88\%). This is different from what was found in Kwan's study, in which Strategy 2A counter claiming (i.e., critically pointing out a problem or weakness in current epistemic practices) was the dominant strategy in the doctoral thesis literature reviews. The Chinese master students' preference of gap-indicating over counter-claiming is not surprising, because observing paucity or inadequacy in current knowledge is academically less demanding than finding flaws, problems, or weakness in the existent knowledge pool or research activities. Therefore, the Chinese master students, who are less epistemically equipped than doctoral students and normally less experienced in the academic community, resort more to gap-indicating than to countering claim to create a research niche for their own studies. For Move 3, Strategy $3 \mathrm{~A}$ announcing the writer's research aims, focuses, questions, or hypotheses is the most frequently used strategy 
which appears in over half of the texts $(52 \%)$.

To summarize, among all the 12 strategies listed in Kwan's model, six strategies are typically used by the Chinese students: strategies1 A, 1B, 1C, 2A, 2B, and 3A, which are therefore chosen for the following discussion of the distribution of evaluation in moves.

Table 3. Occurrence frequency of the moves and sub-level strategies

\begin{tabular}{llll}
\hline & $\begin{array}{l}\text { Number of } \\
\text { move/strategy }\end{array}$ & texts with & the \\
Percentage of texts with the move/strategy
\end{tabular}

Note: total number of texts $=25$.

\section{Distribution of Evaluation in Different Generic Stages}

\subsection{Evaluation in Move 1}

\subsubsection{Attitude}

Table 4 demonstrates a consistent pattern of attitude across the three strategies of Move 1 in the texts: 1) Predominant appreciation over judgment and affect in terms of attitude type: $84.5 \%$ appreciation in Strategy $1 \mathrm{~A}$, $84.2 \%$ in Strategy 1B, and $76.8 \%$ in Strategy 1C. This tells that the Chinese students prefer to evaluate the social value of entities rather than judge human characters or behaviors or express personal feelings when constructing the research territory. 2) Preference of inscribed attitude over encoded attitude: $70.3 \%$ inscribed attitude in Strategy 1A, $58.3 \%$ in Strategy 1B, and $60.7 \%$ in Strategy 1C. This means the students resort more to explicit means to demonstrate their evaluations than implicit ways when arguing for their study objects. 3) Positive attitude far outnumbers negative attitude: $78.5 \%$ positive attitude in Strategy 1A, 94.7\% in Strategy 1B, and $78.9 \%$ in Strategy $1 \mathrm{C}$, indicating the dominance of positive evaluation in Move 1. 
Table 4. Mean frequency and percentage distribution of attitude in Move 1

\begin{tabular}{|c|c|c|c|c|c|c|c|}
\hline & \multicolumn{2}{|c|}{ Strategy 1A } & \multicolumn{2}{|c|}{ Strategy 1B } & \multicolumn{2}{|c|}{ Strategy 1C } \\
\hline & & $/ \mathbf{k}$ & $\%$ & $/ \mathbf{k}$ & $\%$ & $/ \mathbf{k}$ & $\%$ \\
\hline \multirow{3}{*}{ Type } & Affect & $0.1(0.1)$ & $0.3(0.9)$ & $0.0(0.0)$ & $0.0(0.0)$ & $0.1(0.1)$ & $0.5(2.0)$ \\
\hline & Judgment & $1.4(1.1)$ & $15.0(8.3)$ & $0.3(0.8)$ & $15.8(12.4)$ & $1.7(1.4)$ & $22.7(10.8)$ \\
\hline & Appreciation & $7.4(3.4)$ & $84.7(8.7)$ & $1.6(1.2)$ & $84.2(12.7)$ & $5.7(3.5)$ & $76.8(11.3)$ \\
\hline \multicolumn{2}{|l|}{ Total } & $8.8(4.3)$ & $100.0(0.0)$ & $1.9(1.8)$ & $100.0(0.0)$ & $7.5(4.4)$ & $100.0(0.0)$ \\
\hline \multirow{2}{*}{ Mode } & Inscribed & $6.1(2.8)$ & $70.3(11.0)$ & $1.3(1.7)$ & $58.3(37.3)$ & $4.5(2.7)$ & $\begin{array}{l}60.7 \\
(15.4)\end{array}$ \\
\hline & Evoked & $2.8(2.0)$ & $29.7(11.0)$ & $0.6(0.4)$ & $41.7(37.3)$ & $2.9(2.1)$ & $\begin{array}{l}39.3 \\
(15.4)\end{array}$ \\
\hline \multicolumn{2}{|l|}{ Total } & $8.8(4.3)$ & $100.0(0.0)$ & $1.9(1.8)$ & $100.0(0.0)$ & $7.5(4.4)$ & $100.0(0.0)$ \\
\hline \multirow{2}{*}{ Polarity } & Positive & $6.9(3.5)$ & $78.5(12.9)$ & $1.8(1.7)$ & $94.7(6.0)$ & $5.8(3.7)$ & $78.9(15.8)$ \\
\hline & Negative & $1.9(1.5)$ & $21.5(12.9)$ & $0.1(0.2)$ & $5.3(6.0)$ & $1.6(1.7)$ & $21.1(15.8)$ \\
\hline \multicolumn{2}{|l|}{ Total } & $8.8(4.3)$ & $100.0(0.0)$ & $1.9(1.8)$ & $100.0(0.0)$ & $7.5(4.4)$ & $100.0(0.0)$ \\
\hline
\end{tabular}

Note. $/ \mathrm{k}=$ mean per 1,000 words. $\%=$ percentage. $\quad()=$ standard deviation.

Strategy $1 \mathrm{~A}$ involves giving background information of the target topic by defining terms, explaining theories and models, and introducing the current state of knowledge by accounting some common beliefs in the field. A close examination reveals that, when arguing for the significance of the theme or theme-related topics, the Chinese students either positively evaluate the theme or theme-related topics as important or beneficial as in [1], or negatively assess them as difficult, complex, or problematic as in [2]. In both cases, the writer means to show that the object of study is worthy of investigation. When giving general accounts of the disciplinary knowledge advancement or explaining models or theories, they most often employ explicit (occasionally implicit) positive appreciations as in [3] and [4].

[1]. Metacognitive strategies are essential [Appreciation + ] in successful language learning for three reasons. Firstly, by using a metacognitive strategy .... increases their chances of success[Appreciation +]. The second benefit [Appreciation +] of metacognitive strategies is that ... The third reason why metacognitive strategies are important [Appreciation +$]$ is that they develop students' independence. ... Meanwhile, Anderson (2002) points out that the use of metacognitive strategies ...can lead to more profound [Appreciation +$]$ learning and improved [Appreciation +] performance. ... Hence it is essential [Appreciation +] for teachers and learners to give more attention to the understanding of metacognitive strategies.(09 SHISU P41)

[2]. The verbal suffix "le" or "guo" has often been characterized as ...; for Chinese learners of English, this kind of feature is quite similar to the functions and meanings of the simple past tense and the present perfect aspect in English, this is especially the case with "le", ..., therefore, this causes many misuses [Appreciation -] of the two tenses in English during the course of their learning, and this kind of confusion[Appreciation-] also constitutes great difficulties [Appreciation-] for them in the acquisition of English tense and aspect. Obviously, due to this, ..., the uses of Chinese "le" will be the main focus to be discussed here ... (07 SHISU P43)

[3]. In the last decade or so, the field of applied linguistics has witnessed a significant [Appreciation +] progress [Appreciation + ] towards new $\boldsymbol{t}[$ Appreciation + ] understandings of both language and learning (e.g. Firth and Wagner 1997; ...). (07 FJNU P11)

[4]. Roelofs (1992) (see also Levelt et al., 1999) have proposed one of the more influential [Appreciation +] theories of speech production. This theory has two remarkable [Appreciation +] properties. First, the theory covers an impressively [Appreciation + ] broad scope. Second, this theory has been programmed into a computer model, which is exquisitely explicit [Appreciation +] both in terms of its assumption about lexical representation types and lexical retrieval processes in speech production. (09 FJNU P8) 
Strategy 1B involves direct declaration of the centrality of the writer's themes and it is found the Chinese students often make what Kwan (2006) termed "thesis-internal claims" (p. 40). That is, they explicitly asserts the importance/necessity to review the themes of their theses as in [5]. Naturally, positive values instead of negative ones are typically encoded, which explains the high percentage of positive attitude (94.7\%) in this strategy.

[5]. Since..., it is necessary [Appreciation: valuation+] to review all of the relevant theoretical and empirical research, which justifies the necessity [Appreciation: valuation+] and significance [Appreciation: valuation+] of the present study. (10 FINU P1)

Strategy $1 \mathrm{C}$ serves to review previous studies with regard to aspects like procedures, materials, subjects, and results (Kwan, 2006). It is discovered that the Chinese students often evaluate the procedural aspects of the reviewed studies to flag the reader to take a positive or negative attitude towards the validity and reliability of the studies. For instance, in [6], the writer encodes a positive judgment via the expression she analyzes... in detail, which signifies that Xu's study is a reliable one because it is done in a detailed way. The Chinese students also often assess prior studies' social significance as in [7]. While both positive and negative evaluations can be encoded when assessing the procedural aspects and social value of the reviewed studies, the Chinese students only make positive evaluations when it comes to other researchers (see [8]).

[6]. Xu Guozhen (2003: 46)... She analyzes the influences and restrictions in detail [Judgment: tenacity +] from four aspects.... (07 SWU P31)

[7]. $\mathrm{Xu}$ touches upon the virgin land of parody research and she offers us some different $t$ [Appreciation: valuation+] perspectives from which we can have a better[Appreciation: reaction+] understanding of parody. Her discussion is significant [Appreciation: valuation + ] as well as progressive [Appreciation: valuation + ], which can be a good [Appreciation: reaction+] reference for our further study..., though the reasoning process is somewhat too rough [Appreciation: composition-] and a little abstract [Appreciation: composition-](07 SWU P31)

[8]. Schiffrin was an influential [Judgment: capacity+] scholar in 1980s who made ... analysis of DMs. (09 FJNU P17)

\subsubsection{Graduation}

Table 5 displays that grading up the values is overwhelmingly favored by the students, which accounts for $87.4 \%$ of the graduation instantiations in strategies $1 \mathrm{~A}$ and $1 \mathrm{C}$, and $97.6 \%$ in $1 \mathrm{~B}$. This implies that the Chinese students tend to increase their commitments to the construed values to display their confidence and assertiveness when arguing for their study objects.

Table 5. Mean frequency and percentage distribution of graduation in Move 1

\begin{tabular}{|c|c|c|c|c|c|c|c|c|}
\hline & \multicolumn{2}{|c|}{ Strategy 1A } & \multicolumn{2}{|c|}{ Strategy 1B } & \multicolumn{2}{|c|}{ Strategy 1C } \\
\hline & & & $/ \mathbf{k}$ & $\%$ & $/ \mathbf{k}$ & $\%$ & $/ \mathbf{k}$ & $\%$ \\
\hline \multirow{2}{*}{\multicolumn{2}{|c|}{ Orientation }} & Up-scaling & $3.9(2.0)$ & $87.4(8.0)$ & $0.7(0.5)$ & $97.6(5.8)$ & $3.5(2.3)$ & $\begin{array}{l}87.4 \\
(11.2)\end{array}$ \\
\hline & & Down-scaling & $0.5(0.3)$ & $12.6(8.0)$ & $0.02(0.1)$ & $2.4(5.8)$ & $0.5(0.7)$ & $\begin{array}{l}12.6 \\
(11.2)\end{array}$ \\
\hline \multicolumn{3}{|l|}{ Total } & $4.4(2.2)$ & $\begin{array}{l}100.0 \\
(0.0)\end{array}$ & $0.7(0.5)$ & $\begin{array}{l}\text { 100.0 } \\
(0.0)\end{array}$ & $4.0(2.6)$ & $\begin{array}{l}\text { 100.0 } \\
(0.0)\end{array}$ \\
\hline \multirow{5}{*}{ Type } & \multirow{5}{*}{ Force } & Number & $1.4(0.8)$ & $\begin{array}{l}31.8 \\
(13.3)\end{array}$ & $0.2(0.1)$ & $\begin{array}{l}28.6 \\
(27.2)\end{array}$ & $1.5(1.3)$ & $\begin{array}{l}37.5 \\
(16.4)\end{array}$ \\
\hline & & Mass & $0.2(0.3)$ & $4.5(5.9)$ & $0.0(0.0)$ & $0.0(0.0)$ & $0.3(0.3)$ & $7.5(6.2)$ \\
\hline & & Extent & $0.8(0.7)$ & $\begin{array}{l}18.2 \\
(10.7)\end{array}$ & $0.2(0.3)$ & $\begin{array}{l}28.6 \\
(19.3)\end{array}$ & $0.7(0.5)$ & $\begin{array}{l}17.5 \\
(10.5)\end{array}$ \\
\hline & & Quality & $1.2(0.7)$ & $\begin{array}{l}27.3(19.3 \\
)\end{array}$ & $0.3(0.2)$ & $\begin{array}{l}42.8 \\
(29.3)\end{array}$ & $0.7(0.7)$ & $\begin{array}{l}17.5 \\
(16.3)\end{array}$ \\
\hline & & Process & $0.3(0.4)$ & $6.8(7.0)$ & $0.0(0.0)$ & $0.0(0.0)$ & $0.5(0.4)$ & $\begin{array}{l}12.5 \\
(12.0)\end{array}$ \\
\hline
\end{tabular}




\begin{tabular}{l|l|ll|ll|ll}
\hline & Focus & $0.5(0.5)$ & $11.4(8.1)$ & $0.0(0.1)$ & $0.0(0.7)$ & $0.3(0.3)$ & $7.5(7.1)$ \\
\hline Total & $\mathbf{4 . 4 ( 2 . 2 )}$ & $\begin{array}{l}\mathbf{1 0 0 . 0} \\
\mathbf{( 0 . 0 )}\end{array}$ & $\mathbf{0 . 7 ( 0 . 5 )}$ & $\begin{array}{l}\mathbf{1 0 0 . 0} \\
(\mathbf{0 . 0})\end{array}$ & $\mathbf{4 . 0 ( 2 . 6 )}$ & $\begin{array}{l}\mathbf{1 0 0 . 0} \\
\mathbf{( 0 . 0 )}\end{array}$ \\
\hline
\end{tabular}

Note. $/ \mathrm{k}=$ mean per 1,000 words. $\%=$ percentage. $\quad()=$ standard deviation.

With regard to graduation type, grading the number (31.89\%), the quality $(27.3 \%)$, and the extent $(18.2 \%)$ are the three most frequently exploited graduation resources in Strategy 1A. The Chinese students often increase the number of scholars who showed interests in the topic as in [9], or grade up the extent in time that scholars have been working on the topic as in [10], thus flagging a positive attitude towards the topic. Grading the number or extent is also used to encourage an attitudinal reading of the introduced models, theories, classifications, hypotheses, or beliefs in the relevant field as in [11].

[9]. We find that many scholars [Force: number $\uparrow$ ] $\boldsymbol{t}$ [Appreciation + ] have ever discussed this issue (parody). For instance, Chen Wangdao (1932: 168) .... Wu Zhankun (1990: 157) points out that .... Apart from them, there are some other scholars who ever discuss this issue, for example, Zhou Lianxi (1991), Wang Chuangao (1994), Wu Rongqiang (2002) and Xu Guozhen (2003) [Force: number $\uparrow$ ] $\boldsymbol{t}$ [Appreciation +]. (07 HNU P6)

[10]. Researchers have been studying metacognition for over twenty years [Force: extent $\uparrow] \boldsymbol{t}[$ Appreciation +$]$. (09 SHISU P20)

[11]. This framework of metacognitive strategies ....and serves the theoretical basis for a great many researches [Force: number $\uparrow$ ] $\boldsymbol{t}$ [Appreciation: valuation+]. (09 SHISU P32)

In Strategy 1B, the remarkably high frequency of up-scaling (97.6\%) is within expectation, as this strategy is used for direct declaration of the importance or centrality of the writer's themes, and up-scaling can make their claims more forceful and compelling. Specifically, the Chinese students mostly grade the quality $(42.7 \%)$ via words like especially, very, particularly to intensify the quality of the centrality of the research themes. Grading the number $(27.4 \%)$ and the extent $(27.4 \%)$ of the range of the authoritative sources to support their own claims of the importance of their themes are also employed. To exemplify, the writer of [12] achieves a strong tone in the claiming that "attribution theory is helpful and feasible in language learning" by intensifying its helpfulness and feasibility as very helpful and feasible, and by grading up the number of studies supporting such a claim as many studies.

[12]. Many [Force: number $\uparrow$ ] t [Appreciation: valuation+] studies demonstrated that the application of attribution theory in language learning is very [Force quality $\uparrow$ ] helpful and feasible. (08 SWU P14)

Similarly, in Strategy 1C, the Chinese students most frequently grade up the number (37.5\%), the quality $(17.5 \%)$, and the extent $(17.5 \%)$ of the attitudinal or experiential values of previous studies. For example, in [13], the writer intensifies the quality of the corpus's comparability as highly to imply that the reviewed study is reliable. Occasionally, they encode negative attitudes towards the reviewed studies, then they would grade down the construed values to mitigate the negative impact, thus making the negative evaluation less face-threatening, as in [14].

[13]. After building GLBCC, a parallel and highly [Force: quality $\uparrow$ ] $\boldsymbol{t}$ [Appreciation: composition+] comparable corpus, Muller (2005) is concentrated on describing .... (10 FJNU P16)

[14]. Furthermore, Xu resumes her further exploration by summarizing the pragmatic reasoning process of parody: “..." .... Her discussion is significant as well as progressive..., though the reasoning process is somewhat [Force: quality $\downarrow$ ] too rough and a little [Force: quality $\downarrow$ ] abstract. (07 SWU P31)

\subsubsection{Engagement}

As Table 6 shows, there are more monoglossia than heteroglossia in strategies $1 \mathrm{~A}(58.9 \%$ monoglossia) and $1 \mathrm{~B}$ (68.2\% monoglossia). The high frequency of monoglossia in Strategy 1B has something to do with the fact that this strategy typically involves solo-voiced assertion about the importance of the writers' themes. Differently, there are more heteroglossia (52.8\%) than monoglossia (47.2\%) in Strategy 1C, which is not beyond expectation since Strategy 1C is pivoted on other voices and positions via typical expressions such as $X$ analyzes/explains/concludes that.... 
Table 6. Mean frequency and percentage distribution of monoglossia vs. heteroglossia in Move 1

\begin{tabular}{l|ll|ll|ll}
\hline & \multicolumn{2}{|l}{ Strategy 1A } & \multicolumn{3}{l|}{ Strategy 1B } & \multicolumn{2}{l}{ Strategy 1C } \\
\cline { 2 - 7 } & /k & $\mathbf{\%}$ & $/ \mathbf{k}$ & $\mathbf{\%}$ & \multicolumn{2}{l}{$/ \mathbf{\%}$} \\
\hline Monoglossia & $16.0(5.5)$ & $\mathbf{5 8 . 9}(8.7)$ & $1.5(1.0)$ & $\mathbf{6 8 . 2}(16.8)$ & $8.7(5.1)$ & $\mathbf{4 7 . 2 ( 1 0 . 1 )}$ \\
\hline Heteroglossia & $11.4(5.0)$ & $\mathbf{4 1 . 1}(8.7)$ & $0.7(1.0)$ & $\mathbf{3 1 . 8}(16.8)$ & $9.7(5.7)$ & $\mathbf{5 2 . 8}(10.1)$ \\
\hline Total & $27.4(9.4)$ & $\mathbf{1 0 0 . 0}(0.0)$ & $2.2(1.4)$ & $\mathbf{1 0 0 . 0}(0.0)$ & $18.4(10.4)$ & $\mathbf{1 0 0}(0.0)$ \\
\hline
\end{tabular}

Note. $/ \mathrm{k}=$ mean per 1,000 words. $\%=$ percentage. $\quad()=$ standard deviation.

The distribution of heteroglossic subcategories in the three strategies of Move 1 is presented in Table 7, which shows there are more heteroglossic formulations used to expand the space for dialogue with alternative voices than to contract the dialogic space: expansion occupies 56.2\% in Strategy 1A, 54.3\% in Strategy 1B, and 65.9\% in Strategy 1C.

Table 7. Mean frequency and percentage distribution of heteroglossic resources in Move 1

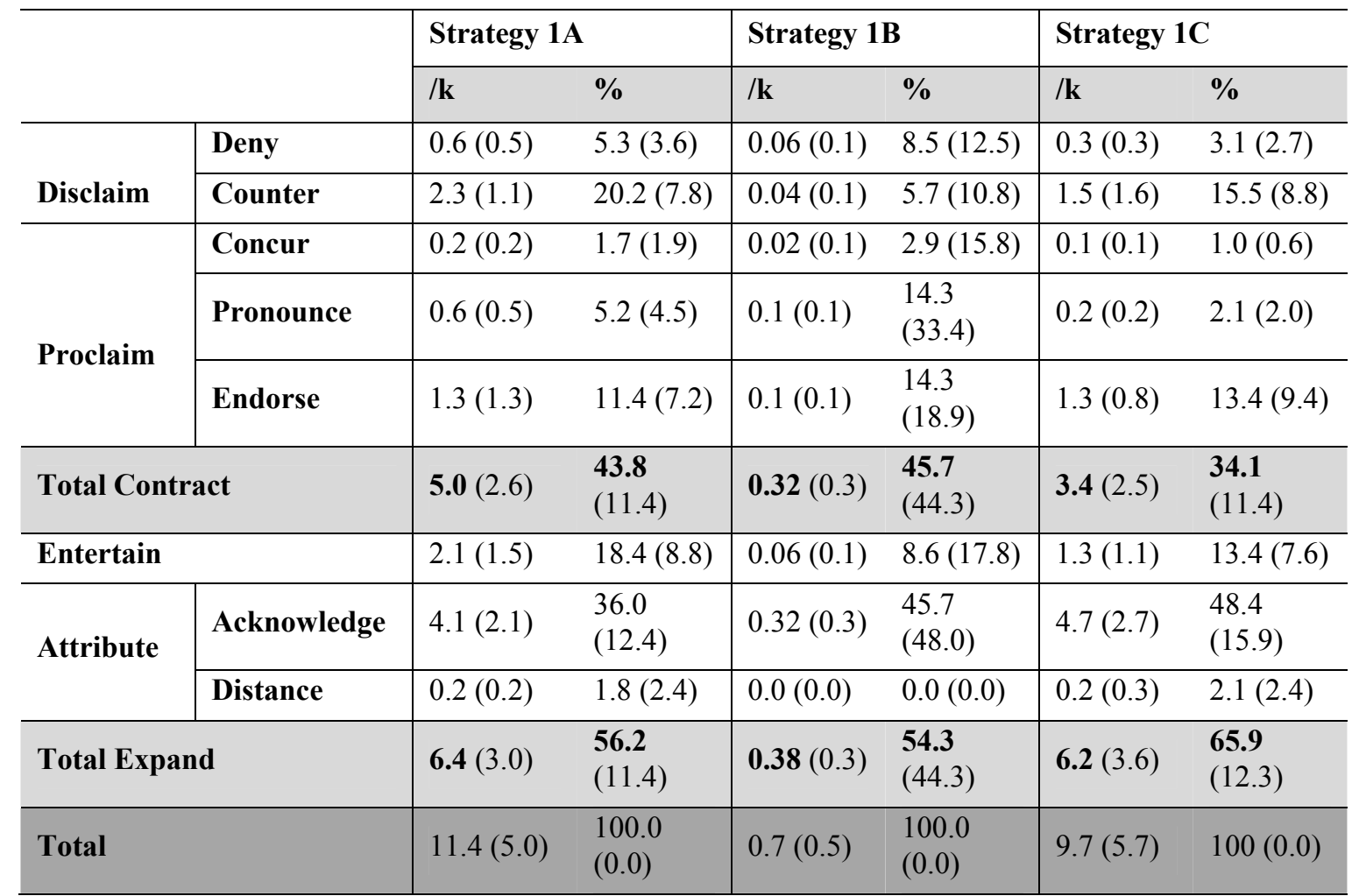

Note. $/ \mathrm{k}=$ mean per 1,000 words. $\%=$ percentage. $\quad()=$ standard deviation.

The higher frequency of expansion in Strategy 1A is probably due to the fact that the writers frequently make neutral acknowledgement $(36.0 \%)$ of the external sources when defining the terminologies and explaining the theme-related notions, as in [15]. Moreover, entertainment (18.4\%) also adds to the frequency of expansion: when the Chinese students make knowledge claims relevant to their themes, they tend to reduce their assertiveness via modal auxiliaries, thus entertaining alternative positions as shown in [16]:

[15]. Stern (1983) gave the definition of strategy [acknowledge] as “...” (p.405). Weinstein and Mayer (1986) thought [acknowledge]that learning strategies are .... According to Rubin (1987) [acknowledge], learning strategies are .... (08 SHISU P2)

[16]. In this case, the properties of LI and L2 phonetic elements may [entertain] be restructured. (07 FJNU P21) 
However, the higher frequency of dialogic expansion (54.3\%) than contraction $(45.7 \%)$ in Strategy 1B is unexpected. It is normally expected the writers narrow the space for negotiation with alternative voices/positions when making authorial claims of centrality of their themes. But a closer look reveals that it is the acknowledgement instantiations (45.7\%) that contribute largely to the frequency of expansion in this strategy. The students are inclined to cite external authoritative voices to make their centrality claims more reliable and convincing as in [17]. Table 7 also shows that pronouncement (14.3\%) is the second most frequently used heteroglossic resource in Strategy 1B, much higher than that in Strategy 1A (5.3\%). This is because claiming the importance of themes are mainly formulated via the writer's authorial statement to indicate his/her substantial commitment to the construed proposition or evaluative values, as in [18]:

[17]. Most researchers believe [acknowledge] that effective language learning strategies help students learn a language in a scientific way...Wen Qiufang (1995), ..., holds[acknowledge] that differences in English learning strategies have decisive impact on achievements when the other conditions are the same. At the same time, other researchers, such as Maclntyre \& Noels (1996), upholding similar views [acknowledge] that.... In summary, language learning strategies are really significant in language learning. (09 SHISU P3)

[18]. We could conclude that the tense and aspect system in English plays an essential role in English language. (07 SHISU P2)

In Strategy 1C, Table 7 shows that when reporting on other studies, the Chinese students mostly take a neutral position towards the reviewed studies (acknowledgement: 48.4\%), less frequently they take affirmative positions (endorsement: $13.4 \%$ ), and very rarely they take a doubtful or negative position towards the cited information (distance: $2.1 \%$ ). Examination of the acknowledgment instantiations unveils that when reporting on other research activities' procedures and methods, the Chinese students are apt to use those what Hyland (1999) termed non-factive reporting verbs (i.e., the writer takes a neutral position towards the cited information) such as summarize, analyze, investigate, explore, examine, etc. as in [19].

[19]. Another study by Trofimovich \& Baker (2006) examined [acknowledge] short, medium, and extended L2 experience ... (07 FJNU P24)

When reporting on other researchers' opinions or viewpoints, they also favor non-factive reporting verbs like argue, hold, suggest, explain, conclude, propose, etc. or expressions like in X's opinion, according to X (see [20]), encoding acknowledgement. Less often they use factive reporting verbs (i.e., the writer takes an affirmative position towards the cited information: point out, show, demonstrate), encoding endorsement as in [21]. Occasionally, counter-factive reporting verbs (i.e., the writer takes a doubtful position towards the cited information) like claim are used to indicate their withdrawal of commitment from the cited information (see [22]).

[20]. Katz \& Postal ... They maintain [acknowledge] that ..., the semantic dictionary must also contain entries for the phrase idioms of the language. (08 HNU P22)

[21]. Phillips (1991) also points out that [endorse] language anxiety is what a language student experiences on a daily basis. (08 NNU P31)

[22]. Nunan (1991) claims [distance] that the amount of teacher talk should be appropriate so that students could get a chance to produce output. (11 SWU P18)

When reporting on other studies' findings and results, the Chinese students often use non-factive reporting verbs like find, indicate or report to implicate their neutral positions as in [23]. Sometimes factive reporting verbs like show and reveal are also used to indicate the writer's agreement with the reported findings as in [24]:

[23]. In a meta-analysis of self-efficacy research published between 1977 and 1988, Multon, Brown \& Lent (1991) find [acknowledge], ... They report that [acknowledge] ... (08 NNU P16)

[24]. Bardovi-Harlig and Reynolds (1995) investigate ...this study shows that [endorse] the acquisition of the simple past tense in English is not a unitary phenomenon, but that it proceeds in stages. (07 SHISU P51)

\subsection{Evaluation in Move 2}

\subsubsection{Attitude}

Consistent with that in Move 1, appreciation is the dominant attitude type in Strategy 2A (80.7\%) and Strategy 2B (80.0\%), followed by judgment and affect (see Table 8). In terms of attitude polarity, there are more negative attitudes in Move 2: $65.4 \%$ in Strategy 2A and 58.6\% in Strategy 2B. This distribution, though different from that in Move 1, is not beyond prediction. Move 1 aims to argue for the object of study, therefore more positive evaluations are expected if the writer wish to convince the reader that his/her object of study is worthwhile. 
Move 2 is to argue for a need for new knowledge in a field, accordingly, the writer needs to encode more negative evaluations of some or part of the current academic pursuits as weak, problematic, or insufficient.

Table 8. Mean frequency and percentage distribution of attitude in Move 2

\begin{tabular}{|c|c|c|c|c|c|}
\hline & & \multicolumn{2}{|c|}{ Strategy 2A } & \multicolumn{2}{|c|}{ Strategy 2B } \\
\hline & & $/ \mathbf{k}$ & $\%$ & $/ \mathbf{k}$ & $\%$ \\
\hline \multirow{3}{*}{ Type } & Affect & $0.02(0.1)$ & $0.8(2.2)$ & $0.0(0.0)$ & $0.0(0.0)$ \\
\hline & Judgment & $0.48(0.5)$ & $18.5(14.4)$ & $0.3(0.2)$ & $20.0(20.6)$ \\
\hline & Appreciation & $2.1(0.9)$ & $80.7(13.7)$ & $1.2(1.1)$ & $80.0(20.6)$ \\
\hline \multicolumn{2}{|l|}{ Total } & $2.6(1.1)$ & $100.0(0.0)$ & $1.5(1.1)$ & $100.0(0.0)$ \\
\hline \multirow{2}{*}{ Mode } & Inscribed & $1.8(0.9)$ & $68.3(12.7)$ & $0.5(0.5)$ & $33.3(31.9)$ \\
\hline & Evoked & $0.8(0.4)$ & $31.7(12.7)$ & $1.0(0.9)$ & $66.7(31.9)$ \\
\hline \multicolumn{2}{|l|}{ Total } & $2.6(1.1)$ & $100.0(0.0)$ & $1.5(1.1)$ & $100.0(0.0)$ \\
\hline \multirow{2}{*}{ Polarity } & Positive & $0.9(0.6)$ & $34.6(21.2)$ & $0.6(0.5)$ & $41.4(24.9)$ \\
\hline & Negative & $1.7(1.0)$ & $65.4(21.2)$ & $0.9(0.7)$ & $58.6(24.9)$ \\
\hline \multicolumn{2}{|l|}{ Total } & $2.6(1.1)$ & $100.0(0.0)$ & $1.5(1.1)$ & $100.0(0.0)$ \\
\hline
\end{tabular}

Note. $/ \mathrm{k}=$ mean per 1,000 words. $\%=$ percentage. $\quad()=$ standard deviation.

A scrutiny of the data reveals that the Chinese students generally follow one pattern to realize the aim of creating a research niche in Move 2: first evaluate positively, and then disrupt the evaluative prosody signaled by conjunctions like however, but to evaluate negatively, as exemplified in [25]. Such a "first positive, then negative" strategy is actually a common practice in academic discourse, functioning as a politeness strategy to lessen the negative impact on the appraised and to help the writer to establish an objective and professional image when "finger-pointing" the current situation.

[25]. From the above discussion of irony, it is clear that scholars in different fields have studied irony from various perspectives, and have already contributed [Appreciation: valuation+] a lot to the comprehension of irony. Nevertheless, There still exist drawbacks [Appreciation: valuation-] and limitations [Appreciation: valuation-] in their studies, and there are a lot of problems [Appreciation: valuation-] unsolved as discussed previously. (10 HNU P56)

In terms of attitude mode, Table 8 shows that most of the attitude instantiations are inscribed (68.3\%) in Strategy 2A. This is out of expectation, since this strategy is to find "faults" in the current literature and the writers are supposedly to do this in an indirect and implicit way, given the fact that "fault-finding" is a very face-threatening act even for the purpose of academic advancement. Thus, the dominance of inscribed attitude in Strategy 2A can be seen as a reflection of the Chinese students" overly directness in "fault-finding". For example, in [26], the writer encodes a series of negative inscriptions as far from actual needs, shortcomings, disadvantages without elaborating on these asserted negative evaluations in the co-text, therefore he/she might sound bold and imposing to professional readers. In Strategy 2B, there are more evoked attitudes (66.7\%) than inscribed ones (33.3\%). This implies that the Chinese students resort more to implicit ways (mainly via grading, as in [27]) when indicating the scarcity or lack of knowledge in a particular area.

[26]. Besides that, our present research is also far from the actual needs [Appreciation: valuation-] in China's real foreign language classroom. These studies also show that there are still some shortcomings[Appreciation: valuation-] and disadvantages [Appreciation: valuation-] in domestic research on foreign language classroom interaction and language teaching and learning. (11 NNU P18)

[27]. Overall, much [Force: number $\uparrow$ ] $\boldsymbol{t}$ [Appreciation: valuation+] research had been done in.... There has been no study [Force: number $\downarrow$ ] $\boldsymbol{t}$ [Appreciation: valuation-] exclusively using Mainland Chinese college learners of English as its subjects. (07 NNU P42) 


\subsubsection{Graduation}

In Strategy 2A, the Chinese students predominantly prefer grading up $(82.3 \%)$ the values, and they most frequently grade the number $(32.2 \%)$, the quality $(23.3 \%)$, and the extent $(16.7 \%)$ of the construed values (see Table 9).

Table 9. Mean frequency and percentage distribution of graduation in Move 2

\begin{tabular}{|c|c|c|c|c|c|c|}
\hline & & & \multicolumn{2}{|c|}{ Strategy $2 \mathrm{~A}$} & \multicolumn{2}{|c|}{ Strategy 2B } \\
\hline & & & $/ \mathbf{k}$ & $\%$ & $/ \mathbf{k}$ & $\%$ \\
\hline \multirow{2}{*}{\multicolumn{2}{|c|}{ Orientation }} & Up-scaling & $0.7(0.4)$ & $82.3(20.7)$ & $0.6(0.7)$ & $54.5(26.5)$ \\
\hline & & Down-scaling & $0.2(0.2)$ & $17.7(20.7)$ & $0.5(0.4)$ & $45.5(22.9)$ \\
\hline \multicolumn{3}{|l|}{ Total } & $0.9(0.52)$ & $100.0(0.0)$ & $1.1(1.0)$ & $100.0(0.0)$ \\
\hline \multirow{6}{*}{ Type } & \multirow{5}{*}{ Force } & Number & $0.29(0.2)$ & $32.2(26.0)$ & $0.69(0.7)$ & $61.1(30.4)$ \\
\hline & & Mass & $0.1(0.1)$ & $11.1(30.6)$ & $0.05(0.1)$ & $4.4(8.5)$ \\
\hline & & Extent & $0.15(0.2)$ & $16.7(16.3)$ & $0.15(0.2)$ & $13.3(17.4)$ \\
\hline & & Quality & $0.21(0.3)$ & $23.3(18.1)$ & $0.09(0.1)$ & $8.0(18.1)$ \\
\hline & & Process & $0.05(0.1)$ & $5.6(8.9)$ & $0.05(0.1)$ & $4.4(8.9)$ \\
\hline & \multicolumn{2}{|l|}{ Focus } & $0.1(0.2)$ & $11.1(10.2)$ & $0.1(0.2)$ & $8.8(7.0)$ \\
\hline \multicolumn{3}{|l|}{ Total } & $0.9(0.5)$ & $100.0(0.0)$ & $1.1(1.0)$ & $100.0(0.0)$ \\
\hline
\end{tabular}

Note. $/ \mathrm{k}=$ mean per 1,000 words. $\%=$ percentage. $\quad()=$ standard deviation.

As discussed earlier, negative evaluation is a serious face-threatening act (Marshall, 2009) and a professional and cautious writer would normally lessen the negative impact. Nonetheless, the abundance of graduation used for amplification and little for mitigation in this strategy implies that the students tend to be bold in making negative evaluations. For example, in [28], the writer amplifies his/her investment in the construed negative values lagged behind as lagged far behind, thus making the negative impact even more face-threatening. Normally, a mitigated negative evaluation as in [29] would be easier to be accepted by the reader.

[28]. Study on middle schools is lagged far [Force: quality $\uparrow$ ] behind. (07 SWU P57)

[29]. Researches pertaining to this topic in China are comparatively [Force: quality $\downarrow$ ] weak and the results are inconsistent. (08 FJNU P38)

In Strategy 2B, though up-scaling (54.5\%) outnumbers down-scaling(45.5\%), there is an obvious increase in the ratio of down-scaling, which is higher than that in strategies $1 \mathrm{~A}, 1 \mathrm{~B}, 1 \mathrm{C}$ and $2 \mathrm{~A}$. In terms of the graduation type, grading the number $(61.1 \%)$ is the most frequently exploited type. It is found that the Chinese students typically use linguistic signals like much, many, most, little, few, and no, to grade up or down the construed values to indicate a gap in knowledge, as in [30].

[30]. However, the participants involved in these studies were mainly ..., few [Force: number $\downarrow$ ] $\boldsymbol{t}$ [Appreciation: valuation-] were concerned with intermediate or advanced learners (Bardovi-Harlig, 1989); .... And much [Force: number $\uparrow$ ] $\boldsymbol{t}$ [Appreciation: valuation+] attention has been focused on the simple past tense and the present perfect aspect separately; few [Force: number $\downarrow$ ] $\boldsymbol{t}$ [Appreciation: valuation-] have combined the two together. (07 SHISU P52)

\subsubsection{Engagement}

Table 10 reveals that there are more monoglossia than heteroglossia in Strategy 2A (68\% vs.32\%) and Strategy 2B (71.4\% vs. $28.6 \%)$. 
Table 10. Mean frequency and percentage distribution of monoglossia vs. heteroglossia in Move 2

\begin{tabular}{|c|c|c|c|c|}
\hline & \multicolumn{2}{|c|}{ Strategy 2A } & \multicolumn{2}{|c|}{ Strategy 2B } \\
\hline & $/ \mathbf{k}$ & $\%$ & $/ \mathbf{k}$ & $\%$ \\
\hline Monoglossia & $2.2(1.1)$ & $\mathbf{6 8 . 0}(14.1)$ & $1.5(1.0)$ & $71.4(16.6)$ \\
\hline Heteroglossia & $1.0(0.5)$ & $32.0(14.1)$ & $0.6(0.5)$ & $28.6(16.6)$ \\
\hline Total & $3.2(1.4)$ & $100.0(0.0)$ & $2.1(1.4)$ & $100.0(0.0)$ \\
\hline
\end{tabular}

Note. $/ \mathrm{k}=$ mean per 1,000 words. $\%=$ percentage. $\quad()=$ standard deviation.

The dominance of monoglossica in Move 2 is within expectation because finding weakness (Strategy 2A) or indicating gaps (Strategy 2B) in the current literature is typically represented in the writer's solo-voiced statements and assertions, which present the writer's claims as true and factual and thus help to align the reader with the construed propositions and evaluative values as in [31].

[31]. Though the study of metaphor from different perspectives has been a lot much, there are only a few researches on the conceptual metaphors in political speeches. Thus, the research carried out in this thesis seems quite necessary. (11 SHISU P14)

As for the heteroglossic instantiations, dialogic contractions are predominant in Move 2: $89.5 \%$ in Strategy 2A and $82.2 \%$ in Strategy $2 \mathrm{~B}$, as shown in Table 11. This is also within expectation because the writer needs to create a research niche in Move 2, accordingly, he/she is not supposed to frequently open up spaces for dialogues and negotiations that might be against this end.

Table 11. Mean frequency and percentage distribution of heteroglossic resources in Move 2

\begin{tabular}{|c|c|c|c|c|c|}
\hline & & \multicolumn{2}{|c|}{ Strategy 2A } & \multicolumn{2}{|c|}{ Strategy 2B } \\
\hline & & $/ \mathbf{k}$ & $\%$ & $/ \mathbf{k}$ & $\%$ \\
\hline \multirow[b]{2}{*}{ Disclaim } & Deny & $0.1(0.1)$ & $10.5(14.3)$ & $0.02(0.1)$ & $3.2(5.1)$ \\
\hline & Counter & $0.6(0.3)$ & $63.2(27.0)$ & $0.34(0.3)$ & $54.8(37.4)$ \\
\hline \multirow{3}{*}{ Proclaim } & Concur & $0.0(0.0)$ & $0.0(0.0)$ & $0.0(0.0)$ & $0.0(0.0)$ \\
\hline & Pronounce & $0.1(0.2)$ & $10.5(16.0)$ & $0.1(0.1)$ & $16.1(20.0)$ \\
\hline & Endorse & $0.05(0.2)$ & $5.3(8.2)$ & $0.05(0.1)$ & $8.1(11.0)$ \\
\hline \multicolumn{2}{|c|}{ Total Contract } & $\mathbf{0 . 8 5}(0.4)$ & $89.5(14.0)$ & $\mathbf{0 . 5 1}(0.4)$ & $82.2(35.2)$ \\
\hline \multicolumn{2}{|l|}{ Entertain } & $0.1(0.1)$ & $10.5(9.3)$ & $0.11(0.1)$ & $17.8(17.8)$ \\
\hline \multirow{2}{*}{ Attribute } & Acknowledge & $0.0(0.0)$ & $0.0(0.0)$ & $0.0(0.0)$ & $0.0(0.0)$ \\
\hline & Distance & $0.0(0.0)$ & $0.0(0.0)$ & $0.0(0.0)$ & $0.0(0.0)$ \\
\hline \multicolumn{2}{|c|}{ Total Expand } & $0.1(0.2)$ & $10.5(12.3)$ & $\mathbf{0 . 1 1}(0.2)$ & $17.8(17.8)$ \\
\hline \multicolumn{2}{|l|}{ Total } & $0.95(5.7)$ & $100.0(0.0)$ & $0.62(0.5)$ & $100.0(0.0)$ \\
\hline
\end{tabular}

Note. $/ \mathrm{k}=$ mean per 1,000 words. $\%=$ percentage. $\quad()=$ standard deviation.

Among the contractive resources, countering is the most frequently used resource, which occupies $63.2 \%$ of the heteroglossic instantiations in Strategy 2A and 54.8\% in Strategy 2B. Such high frequent use is mainly due to the constant employment of conjunctions (e.g., though, even though, however, still, yet) to first acknowledge and then counter a predicted position or belief as well as to signal a shift of evaluative prosody from positive to negative. The following example [32] is listed for exemplification. 
[32]. Reverse transfer has proved its existence with large amount of [Force: number $\uparrow$ ] $t$ [Appreciation: valuation +$]$ proof in various [Force: extent $\uparrow$ ] $t$ [Appreciation: valuation +$]$ dimensions of language, yet [counter] little [Force: mass $\downarrow$ ] $\boldsymbol{t}$ [Appreciation: valuation-]trace was found at the suprasegmental level in phonological subsystem. (07 FJNU P1)

\subsection{Evaluation in Move 3}

\subsubsection{Attitude}

As Table 12 shows, appreciation is the dominant attitude type (66.7\%), followed by judgment $(33.3 \%)$ in Strategy $3 \mathrm{~A}$, which is similar to that in the previous five strategies. But there is no negative attitudes in this strategy. This is reasonable and within expectation, because the aim of Move 3 is to show the reader that the writer's own study is contributive and negative evaluation of the writer's own study runs against this aim and would make the whole thesis endeavor meaningless.

Table 12. Mean frequency and percentage distribution of attitude in Move 3

\begin{tabular}{|c|c|c|c|}
\hline & & \multicolumn{2}{|c|}{ Strategy $3 \mathbf{A}$} \\
\hline & & $/ \mathbf{k}$ & $\%$ \\
\hline \multirow{3}{*}{ Type } & Affect & $0.0(0.0)$ & $0.0(0.0)$ \\
\hline & Judgment & $0.2(0.3)$ & $33.3(34.5)$ \\
\hline & Appreciation & $0.4(0.3)$ & $66.7(39.5)$ \\
\hline \multicolumn{2}{|l|}{ Total } & $0.6(0.4)$ & $100.0(0.0)$ \\
\hline \multirow{2}{*}{ Mode } & Inscribed & $0.36(0.3)$ & $60.0(44.8)$ \\
\hline & Evoked & $0.24(0.3)$ & $40.0(43.2)$ \\
\hline \multicolumn{2}{|l|}{ Total } & $0.6(0.4)$ & $100.0(0.0)$ \\
\hline \multirow{2}{*}{ Polarity } & Positive & $0.6(0.4)$ & $100.0(0.0)$ \\
\hline & Negative & $0.0(0.0)$ & $0.0(0.0)$ \\
\hline \multicolumn{2}{|l|}{ Total } & $0.6(0.4)$ & $100.0(0.0)$ \\
\hline
\end{tabular}

Note. $/ \mathrm{k}=$ mean per 1,000 words. $\%=$ percentage. $\quad()=$ standard deviation.

With regard to attitude mode, the Chinese students express their attitudes more in an explicit way (60.0\%) and less in an implicit way (40.0\%) in Strategy 3A. They tend to foreground their studies as better-designed as in [33], or in terms of social value as in [34].

[33]. Therefore, the tenor of present study is to systematically [Judgment: tenacity + ] re-examine the relationship between phonological short-term memory and vocabulary acquisition with Chinese EFL learners as subjects. (08 FJNU P1)

[34]: Given these considerations, this author has chosen to conduct the present study to provide a picture of the use of the English articles ... and to propose some pedagogical strategies which are supposed to be feasible [Appreciation: valuation+] and practical [Appreciation: valuation+] in the Chinese setting. (07 NNU P41)

\subsubsection{Graduation}

Table 13 shows that almost all the graduation instantiations in Strategy 3A involve grading up the construed values (96.7\%), thus making the writer's argument for the new contribution of their studies compelling and forceful. 
Table 13. Mean frequency and percentage distribution of graduation in Move 3

\begin{tabular}{|c|c|c|c|c|}
\hline & & & \multicolumn{2}{|c|}{ Strategy 3A } \\
\hline & & & $/ \mathbf{k}$ & $\%$ \\
\hline \multirow{2}{*}{\multicolumn{2}{|c|}{ Orientation }} & Up-scaling & $0.29(0.3)$ & $96.7(50.0)$ \\
\hline & & Down-scaling & $0.01(0.1)$ & $3.3(13.4)$ \\
\hline \multicolumn{3}{|l|}{ Total } & $0.3(2.2)$ & $100.0(0.0)$ \\
\hline \multirow{6}{*}{ Type } & \multirow{5}{*}{ Force } & Number & $0.03(0.1)$ & $10.0(14.0)$ \\
\hline & & Mass & $0.01(0.1)$ & $3.3(13.7)$ \\
\hline & & Extent & $0.09(0.1)$ & $30.0(20.3)$ \\
\hline & & Quality & $0.05(0.1)$ & $16.7(29.4)$ \\
\hline & & Process & $0.11(0.2)$ & $36.7(28.9)$ \\
\hline & \multicolumn{2}{|l|}{ Focus } & $0.01(4.6)$ & $3.3(4.6)$ \\
\hline \multicolumn{3}{|l|}{ Total } & $0.3(2.2)$ & $100.0(0.0)$ \\
\hline
\end{tabular}

Note. $/ \mathrm{k}=$ mean per 1,000 words. $\%=$ percentage. $\quad()=$ standard deviation.

For the graduation type, grading the process $(36.7 \%)$ and the extent $(30 \%)$ are the two most frequently employed resources. The students seem especially favor lexis that have infused semantic meanings such as probe into and explore (studying carefully, deeply and thoroughly), and elaborate and expound (explaining in detail and thoroughly) (Hood, 2004). These lexis flag the reader to view the writer's studies as reliable and dependable as in [35].

[35]. We will probe into [Force: process $\uparrow]$ t $\boldsymbol{t}$ Judgment: tenacity + ] the tonal issue of anguage influence other than the language as a whole, by expanding [Force: extent $\uparrow$ ] $\boldsymbol{t}[$ Appreciation: valuation +$]$ a segment-oriented model ..., to see if it also applies to the case in suprasegmental dimension. (07 FJNU P17)

\subsubsection{Engagement}

Table 14 shows the overwhelming presence of monoglossia (84.2\%) in Strategy 3A, which is also within expectation as it is where the writer occupies the already established niche by announcing their own research orientations in solo-voiced statements.

Table 14. Mean frequency and percentage distribution of monoglossia vs. heteroglossia in Move 3

\begin{tabular}{|c|c|c|c|c|c|c|}
\hline & \multicolumn{2}{|c|}{ Monoglossia } & \multicolumn{2}{|c|}{ Heteroglossia } & \multicolumn{2}{|c|}{ Total } \\
\hline & $/ \mathrm{K}$ & $\%$ & & $\%$ & $/ \mathrm{K}$ & $\%$ \\
\hline Mean & 0.9 & 84.2 & 0.5 & 15.8 & 1.4 & 100.0 \\
\hline S.D. & 0.7 & 23.5 & 1.2 & 23.5 & 1.8 & 0.0 \\
\hline
\end{tabular}

Note. $/ \mathrm{k}=$ mean per 1,000 words. $\%=$ percentage. $\quad$ Mean $=$ mean per text. $\quad$ S.D. $=$ standard deviation. 
Table 15. Mean frequency and percentage distribution of heteroglossic resources in Move 3

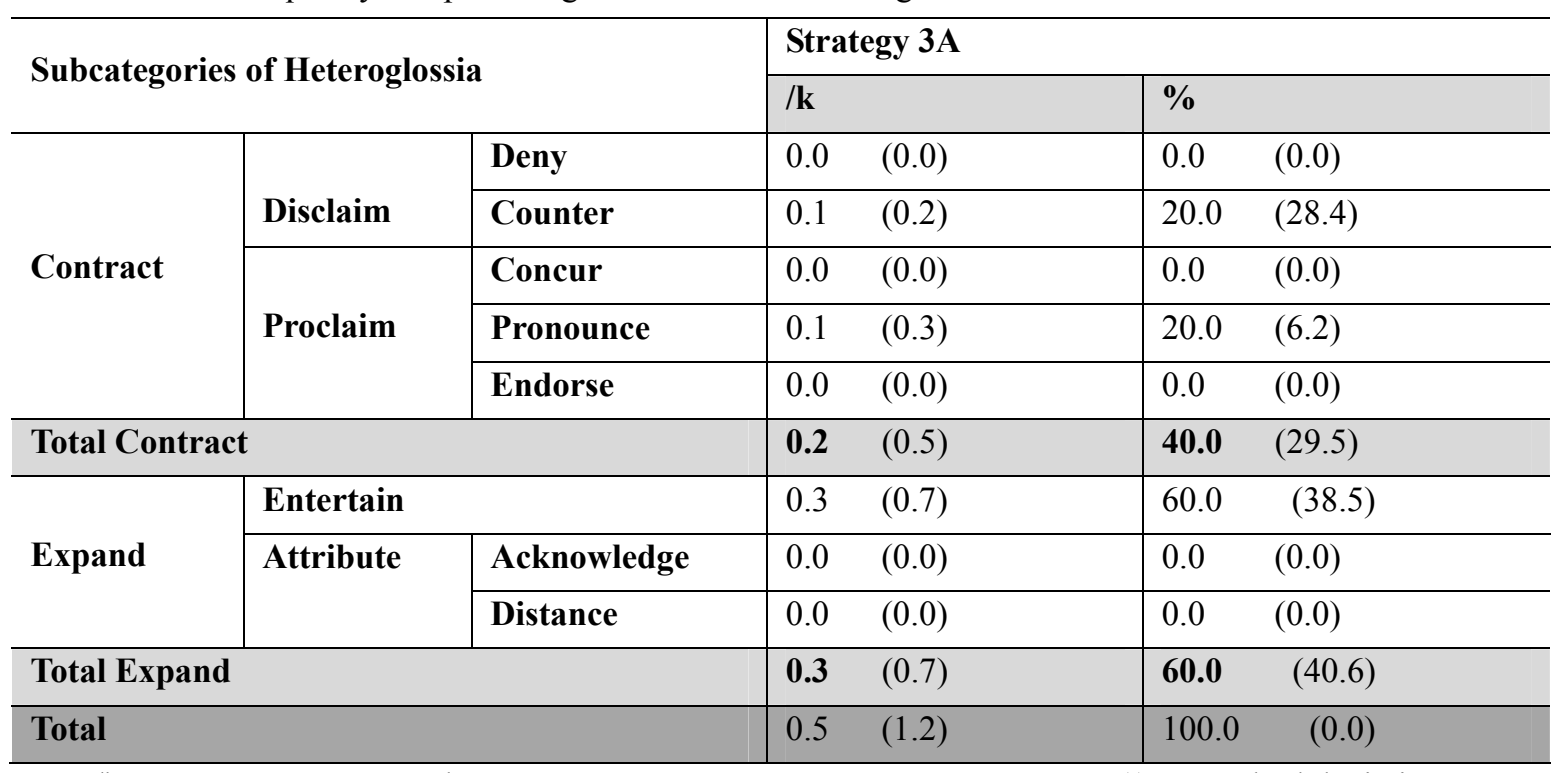

Note. $/ \mathrm{k}=$ mean per 1,000 words. $\%=$ percentage. $\quad$ Mean $=$ mean per text. $\quad()=$ standard deviation.

The heteroglossic resources in Strategy $3 \mathrm{~A}$ are presented in Table 15, which displays more dialogic expansions $(60 \%)$ than contractions $(40 \%)$. This is unexpected as dialogues with other voices seem not necessary when the writer "self-praise" their studies. A closer look shows that it is the high frequency of entertainment that contributes to the high percentage of dialogic expansion in this strategy. Here, entertainment functions to mitigate the imposition of the writer's "self-praise" and thus align the reader with the contributions of the writer's study. It is found that some students use modal auxiliaries like might, may to sound less assertive as shown in [36].

[36]. Based on the empirical study on teacher talk, the present thesis attempts to elaborate the realization of teachers' identities from the angle of discourse analysis, which might [entertain] open up a new perspective by adding sociological factors. (11 SWU P26)

\subsection{Summary of Evaluation Across the Three Moves}

Basing on the above discussion, a general picture of Chinese MA students' evaluations across the three moves of thesis literature reviews unfolds as follows.

Attitude 1) Appreciation is the attitude type that predominates all the three moves. Such preference is in accordance with the institutionalized nature of academic discourse as found by other studies (e.g., Hood, 2004; Cominos, 2011, Marshall, 2009). 2) The Chinese students prefer to express evaluation more in an explicit way than an implicit way in most rhetorical stages except in Strategy 2B. This finding is different from what was found in previous studies (e.g., Scollon, 1991; Hinkel, 1997) that suggested Chinese students tended to express evaluation in an indirect manner. 3) They are able to well-adjust the attitude polarity to achieve the different purposes of the three moves: more positive attitudes in Move 1 when arguing for their objects of studies, more negative attitudes in Move 2 when arguing for a need for new knowledge, and only positive attitudes in Move 3 when arguing for their own contributions.

Graduation The Chinese students predominantly grade up the construed values in all the three moves, thus making their statements forceful and confident. But there is a marked increase of down-scaling in Strategy 2B which helps to reduce the negative impact of negative evaluation of other studies, and a sharp decrease in strategies $1 \mathrm{~B}$ and $3 \mathrm{~A}$ where down-scaling is not typically expected. Such variation suggests that the Chinese student writers are generally able to manipulate the grading orientation in ways that are conducive to strengthening or weakening their evaluations when necessary.

Engagement The Chinese students tend to overuse monoglossia in most of the rhetorical stages, even including Strategy 1A where the writer is supposed to frequently use the heteroglossic resources of endorse, acknowledgment, or distance when explicating models, theories, terms, and beliefs. Nevertheless, they use heteroglossic resources in a way that is basically beneficial for realizing the aims of the three moves: more 
dialogic expansions than contractions in Move 1 and 3, and more dialogic contractions than expansions in Move 2. Move 1 involves making references to other voices and positions, therefore, more expansions are expected in this stage. Move 3 is to argue that the writer's own studies are contributive and the frequent use of expansive entertainment helps to soften the imposition of the "self-praise". Move 2 expects more dialogic contractions as it is to argue that there is a need for new knowledge in a particular area. To do this, the writer mainly gives commentary remarks on the reported literature and less frequently cites other voices or positions.

To conclude, we may say that the Chinese English-major MA students are generally able to use various evaluative resources in a way that facilitates realizing the purposes of different rhetorical stages in their thesis literature reviews.

\section{Problems and Pedagogical Implications}

\subsection{Problematic employment of evaluation in different moves}

The Chinese student writers, though being advanced EFL learners, also have problems in deploying the generic structure and employing evaluative resources in the thesis literature reviews.

The first problem lies in the disproportionate deployment of the moves and strategies. It is found that Move 1 often occupies an exceedingly large length in the Chinese students' literature reviews while Move 2 is underdeveloped which is often realized via short segments. Some of the students spend almost the whole chapter introducing the current state of knowledge and use only one or two sentences indicating the gaps or weakness in the extant literature. Moreover, within Move 1, Strategy 1A far outnumbers Strategy 1C in length in many texts. Actually, many students spend most spaces on describing theories and notions and give little space to surveying previous studies, thus turning the literature reviews into mere descriptive introductions. Such deployment is obviously not beneficial for weaving a persuasive argument in the texts.

The second problem concerns the inadequate evaluation in Move 2. As Table 16 shows, most of the evaluations are found in Move $1(78.4 / \mathrm{k}$ in total), and there is too sharp a drop in the two strategies of Move $2(11.3 / \mathrm{k}$ in total). We know that evaluation plays a particular crucial role in Move 2 where the writers are supposed to encode typically negative evaluations to assess the extant literature so as to create a research niche. Therefore, the low frequency of evaluative instantiations in Move 2 tells the Chinese students' reluctance to evaluate the extant literature, which is also not beneficial for weaving a strong argument for their own studies.

Table 16. Mean frequency of evaluative resources in the six strategies

\begin{tabular}{lllll}
\hline & Attitude & Graduation & Engagement & Total \\
\hline Strategy 1A & 8.8 & 4.4 & 27.4 & 40.6 \\
Strategy 1B & 1.9 & 0.7 & 2.0 & 4.6 \\
Strategy 1C & 10.8 & 4.1 & 18.3 & 33.2 \\
Strategy 2A & 2.6 & 0.9 & 3.2 & 6.7 \\
Strategy 2B & 1.5 & 1.1 & 2.0 & 4.6 \\
Strategy 3A & 0.6 & 0.3 & 1.4 & 2.3 \\
\hline
\end{tabular}

Note: Normalized frequency per 1,000 words.

The third problem involves making bold and empty negative evaluation, especially in Strategy 2A as discussed in Section 5.2.1. The Chinese students tend to make "big" declarations of the problematic research situation, typically via lexis as drawbacks, limitations, and problems, without providing concrete analysis to support their claims in the co-text, thus sounding less convincing. In addition, the markedly low frequency of down-scaling in Strategy 2A, where the writer is supposed to mitigate the negative evaluations to be polite, shows the Chinese students are rather imposing in pointing out weaknesses of other studies. Such boldness and imposition are not helpful to align the reader, since "scholarly argumentation is not meant to overpower but rather to convince" (Machi \& McEvoy, 2009).

Besides, unintentional "plagiarism", as Groom (2000) pointed out about novice academic writers, is also found among the Chinese student writers, who sometimes do not make explicit reference to external sources. A typical example is that, when explaining a notion or concept, they tend to construct monoglossic formulations without indicating the external source via expressions such as according to $X \ldots$ or in this theory, ...means.... This partly 
accounts for monoglossia far outnumbering heteroglossia in Strategy 1A. Such unintentional plagiarism is probably due to the Chinese students' misunderstanding that the commonly acknowledged notions and beliefs are given facts owned by everyone engaged in the field, and therefore indication of the original sources is not necessary.

\subsection{Pedagogical Implications}

According to the present researcher's informal survey, relevant courses on English academic writing including thesis writing have been offered both in undergraduate and graduate levels in most prominent universities in China. However, the instruction mainly addresses the formatting issues. For example, the overall structure of a thesis, styles to follow in in-text citation and reference list, and some technical means to reach resources, or other broad formatting aspects. The content-related aspects such as how to deploy the internal rhetorical stages in a particular thesis section, or how to exploit evaluation to help build a coherent argument in the thesis are generally expected to be acquired by the students themselves through reading or inference in an "essentially intuitive fashion" (Cominos, 2011, p. 19). Such neglect of content instruction is not confined to China, it actually is a common phenomenon in L1 and L2 English academic writing pedagogy (Cominos, 2011). That explains why some of novice academic writers' difficulties in thesis writing originate from their restricted understanding of the genre, the content parameters of different sections of a thesis, and the necessity to build a coherent argument (e.g., Cadman, 1997; Casanave \& Hubbard, 1992; Bitchener \& Basturkmen, 2006). In particular, novice academic writers are generally inadequately equipped with the knowledge of the persuasive functions of the literature review as well as its characteristics (Bitchener \& Banda, 2007; Turner \& Bitchener, 2008).

Such being the case, the following practices are suggested in teaching English thesis writing: 1) To conduct modeling instruction to inform students of the typical schematic structure of a particular thesis section. The move models of Swales (1990) and Kwan (2006) can be good references to exemplify the possible options to logically structure the literature review. 2) To raise the students' awareness of the importance of demonstrating evaluative positions in thesis writing, and of contriving an extended argument in each section. 3) To explain and model the possible linguistic resources for encoding evaluation in English academic writing. The appraisal taxonomy can be a possible model for reference. It is believed that such explicit instruction on the content aspects helps to turn the complicated and intuitive process of thesis writing into one in which the students are equipped with informed choices (Cominos, 2011).

\section{Acknowledgements}

The work reported in this paper was funded by Guangdong Planning Office of Philosophy and Social Science 2015 Fund Project, China (Project Code: GD15YWW04), and by Innovative School Project in Higher Education of Guangdong, China (Project Code: GWTP-BS-2015-14).

\section{References}

Bitchener, J., \& Banda, M. (2007). Postgraduate students' understanding of the functions of thesis sub-genres: The case of the literature review. New Zealand Studies in Applied Linguistics, 13(2), 89-102.

Bitchener, J., \& Basturkmen, H. (2006). Perceptions of the difficulties of postgraduate L2 thesis students writing the discussion section. Journal of English for Academic Purposes, 5, 4-18. https://doi.org/10.1016/j.jeap.2005.10.002

Cadman, K. (1997). Thesis writing for international students: A question of identity? English for Specific Purposes, 16, 3-14.

Casanave, C., \& Hubbard, P. (1992). The writing assignments and writing problems of doctoral students: Faculty perceptions, pedagogical issues, and needed research. English for Specific Purposes, 11, 33-49. https://doi.org/10.1016/0889-4906(92)90005-U

Chang, P., \& Schleppegrell, M. (2011). Taking an effective authorial stance in academic writing: Making the linguistic resources explicit for L2 writers in the social sciences. Journal of English for Academic Purposes, 10, 140-151. https://doi.org/10.1016/j.jeap.2011.05.005

Cominos, N. (2011). Managing the subjective: Exploring dialogistic positioning in undergraduate essays. Unpublished doctoral dissertation, University of Adelaide, Adelaide, South Australia.

Conrad, S., \& Biber, D. (2000). Adverbial marking of stance in speech and writing. In S. Hunston, \& G. Thompson (Eds.), Evaluation in text: Authorial stance and the construction of discourse (pp. 57-73). Oxford University Press. 
Crane, C. P. (2008). Evaluative choice in advanced L2 writing of German: A genre perspective. Unpublished doctoral dissertation, Georgetown University, Washington.

Dawidowicz, P. (2010). Literature reviews made easy: A quick guide to success. NC: Information Age Publishing Incorporation.

Feak, C. B., \& Swales, J. M. (2009). Telling a research story: Writing a literature review. The University of Michigan Press. https://doi.org/10.3998/mpub.309338

Groom, N. (2000). Attribution and averral revisited: Three perspectives on manifest intertextuality in academic writing. In P. Thompson (Ed.), Patterns and perspectives: Insights for EAP writing practice (pp. 14-25). Reading, UK: Centre for Applied Language Studies, University of Reading.

Halliday, M. A. K. (1994). An introduction to functional grammar (2nd ed.). London: Edward Arnold.

Hart, C. (1998). Doing a literature review. London: SAGE Publications Ltd.

Hart, C. (2001). Doing a literature search: A comprehensive guide for the social sciences. London: Sage Publications.

Hinkel, E. (2005). Hedging, inflating, and persuading in L2 academic writing. Applied Language Learning, 15, 29-53.

Hood, S. (2004). Appraising research: Taking a stance in academic writing. Unpublished doctoral dissertation, University of Technology, Sydney, Australia.

Hyland, K. (2005). Metadiscourse: Exploring interaction in writing. London/New York: Continuum.

Hyland, K., \& Diani, G. (2009). Introduction: Academic evaluation and review genres. In K. Hyland, \& G. Diani (Eds.), Academic evaluation: Review genres in university settings. Basingstoke, UK: Palgrave Macmillan. https://doi.org/10.1057/9780230244290_1

Kwan, B. S. C. (2006). The schematic structure of literature reviews in doctoral theses of applied linguistics. English for Specific Purposes, 25(1), 30-55. https://doi.org/10.1016/j.esp.2005.06.001

Machi, L. A., \& McEvoy, B. T. (2009). The literature review: Six steps to success. California: Corwin Press.

Marshall, C. L. (2009). The role of APPRAISAL in the National Research Foundation (NRF) rating system: Evaluation and instruction in peer reviewer reports. Unpublished master's dissertation, Rhodes University, Grahamstown, Eastern Cape Province, South Africa.

Martin, J. R., \& White, P. R. R. (2005). The language of evaluation. NY: Palgrave Macmillan. https://doi.org/10.1057/9780230511910

O'Connell, F., \& Jin, L. X. (2001). A structural model of literature review: An analysis of Chinese postgraduate students' writing. British Association of Lecturers of English for Academic Purposes Reports. Sheffiled, UK: Sheffield Hallam University.

Scollon, R. (1991). Eight legs and one elbow: Stance and structure in Chinese English composition. Paper presented at International Reading Association, Second North American Conference on Adult and Adolescent Literacy, Banff, Canada.

Swales, J. M. (1990). Genre analysis: English in academic and research settings. Cambridge University Press.

Swales, J. M., \& Lindemann, S. (2002). Teaching the Literature Review to international graduate students. In A. M. Johns (Ed.), Genre in the classroom (pp. 105-119). NJ: Lawrence Erlbaum Associates, Inc.

Turner, E., \& Bitchener, J. (2008). An approach to teaching the writing of literature reviews. zeitschrift-schreiben.eu.

White, P. R. R. (2001). Introductory guide to Appraisal. http://www.grammatics.com/appraisal/Appraisal Guide/Framed/Frame. html

\section{Copyrights}

Copyright for this article is retained by the author(s), with first publication rights granted to the journal.

This is an open-access article distributed under the terms and conditions of the Creative Commons Attribution license (http://creativecommons.org/licenses/by/4.0/). 